\section{Melanoma mortality in Brazil: trends and projections (1998-2032)}

\author{
Mortalidade por melanoma no Brasil: \\ tendências e projeções (1998-2032)
}

Camila Alves dos Santos (https://orcid.org/0000-0001-9856-7977) ${ }^{1}$

Dyego Leandro Bezerra Souza (https://orcid.org/0000-0001-8426-3120) ${ }^{1}$
${ }^{1}$ Departamento de Saúde Coletiva e Nutrição, Centro de Ciências da Saúde, Universidade Federal do Rio Grande do Norte. Av. Sen. Salgado Filho, Lagoa Nova. 59078-970 Natal RN Brasil.camilalvesantos@ gmail.com

\begin{abstract}
Melanoma is the main serious skin cancer, due to its high lethality. This study aimed to make projections and analyze melanoma mortality trends in Brazil. Mortality Information System data were utilized for the period 19982012, which were projected until 2032, using the age-period-cohort model, with software $R$. The analysis of trends was made by Joinpoint regression, with $95 \%$ confidence interval, estimating the annual percentage change. It was revealed higher amounts of deaths in men for all regions. Brazilian trends presented reductions in men $(A P C=$ $-0.4 ; C I 95 \%=-0.6 ;-0.1 ; p<0.01)$ and in women $(A P C=-0.8 ; C I 95 \%=-0.9 ;-0.7 ; p<0.01)$. The Midwest region presented increases for both sexes, while the Southeast region presented reducing trends for both sexes. In the North, there was stability for men and increases followed by stability in women, while the South presented reductions in men and stability in women; finally, the Northeast revealed one joinpoint per sex, with an increase followed by stability in men, and stability followed by reducing trends in women. The highest rates of the country were found in the South and Southeast regions, however, with reducing trends throughout time. Higher mortality trends in men were associated with later diagnoses in this group.

Key words Melanoma, Mortality, Population projections, Trends
\end{abstract}

Resumo O melanoma é o mais grave câncer de pele, devido à alta letalidade. Este estudo objetiva projetar e analisar tendências da mortalidade por melanoma no Brasil. Os dados são do Sistema de Informação sobre Mortalidade, no período de 1998 a 2012, os quais foram projetados até 2032, usando o modelo idade-período-coorte, no software R. A análise de tendências foi feita pela Regressão loglineal (Joinpoint regression), com intervalo de confiança de 95\%, para estimar a porcentagem anual de mudança. Revelou-se maior quantitativo de mortes em homens em todas as regiōes. As tendências no Brasil apontaram para redução em homens (APC $=-0,4$; IC95\% = $-0,6 ;-0,1 ; p<0,01)$ e em mulheres $(A P C=-0,8$; $I C 95 \%=-0,9 ;-0,7 ; p<0,01)$. A região Centro-oeste teve aumento para os dois sexos, em oposição ao Sudeste, com redução em ambos. No Norte, houve estabilidade em homens, e aumento seguido de estabilidade em mulheres, enquanto o Sul teve redução em homens e estabilidade em mulheres; e, por fim, o Nordeste teve um joinpoint em cada sexo, com aumento seguido de estabilidade em homens; e estabilidade seguida de redução em mulheres. As maiores taxas do país foram no Sul e Sudeste, todavia, com tendência a redução ao longo do tempo. A maior mortalidade em homens foi associada ao diagnóstico mais tardio.

Palavras-chave Melanoma, Mortalidade, Projeções de população, Tendências 


\section{Introduction}

Skin melanoma is a type of cancer that is most incident in more developed regions, however, least developed locations present, proportionally, higher mortality rates ${ }^{1,2}$, as diagnoses are usually made at later stages and these locations do not count with the same availability of resources for treatment ${ }^{2}$.

Worldwide, the highest rates are registered in countries with Caucasian population, while lower rates are commonly found in South American and African countries, where pardos (triracial descendants of Europeans, Native Americans, and West Africans) and Afro-American populations predominate ${ }^{3}$. For 2015, global data on melanoma revealed incidence rates of approximately 3.5 new cases per 100,000 inhabitants for men and 3.3 for women. Regarding mortality rates, the same period presented values of 0.92 deaths per 100,000 inhabitants for men and 0.71 for women ${ }^{1}$.

In Brazil, estimates for the year 2015 indicated incidence rates of 3.47 new cases per 100,000 inhabitants for men and 3.07 for women. Mortality rates for the same year were 1.22 deaths per 100,000 inhabitants for men and 0.86 for wom$e^{1}$. In Brazil, skin cancer is the most incident ${ }^{4}$, and melanoma is more aggressive $e^{5}$ than another types of this cancer. Among those exposed to risk factors, professional activities that require sun exposure are highlighted, such as tourism, fishing, agriculture and civil construction. Such activities combine such exposure to high incidence of this radiation. Another important factor is represented by the historical construction of Brazilian population, with European ascendency in some regions (mainly the South ${ }^{6}$ ) and indigenous and Afro-American ascendency in other regions due to colonization (North and Northeast).

Also, it must be mentioned that understanding the profiles of illnesses extrapolates the biologic dimension, reaching the social dimension of vulnerabilities and other mechanisms that form the basis of inequality dynamics and health conditions, since multidisciplinary questions are involved. Therefore, the qualified use of information related to healthcare inequalities is fundamental for health policies and search for equality ${ }^{7}$.

This study focuses on comparing the Brazilian geographic regions, filling gaps in distribution patterns of melanoma mortality and verifying dynamics throughout the years. Estimation of trends is fundamental for the planning and allocation of resources and for the control and sta- bilization of the disease ${ }^{8}$. The hypothesis is that there is an irregular distribution of the disease in the Brazilian territory, considering regional differences and determinants. The main objective of the study presented herein was to analyze the distribution of melanoma mortality by Brazilian region, between 1998 and 2012, and carry out projections until 2032.

\section{Methodology}

An ecological, population-based study is presented herein on melanoma mortality. National and regional information were analyzed, from January 1, 1998 to December 31,2012. Data collection from the Mortality Information System (MIS) occurred between the months of August and October, 2015. Data was available from the Brazilian Unified Health System website (DATASUS). The code utilized was CID C43 - malignant skin melanoma, and the interval between 1998 and 2012 was divided in 5-year periods for data collection 9 . This time period considers the relatively long course of the disease, with the objective of avoiding time biases. Data tabulation considered deaths by residence location, classified by region, sex and age group. These age groups were divided in 5-year periods, except for the last group (over 85 years of age).

Population data were obtained from the Brazilian Institute of Geography and Statistics (Instituto Brasileiro de Geografia e Estatística, IBGE), and the population utilized referred to the year that represented half of the period. Resident populations for each region and Brazil were utilized for years 2000, 2005 and 2010, with population projections utilized for years 2015, 2020, 2025 and 2030, also available from IBGE, per sex and age groups. Population data utilized the same 18 intervals considered for mortality data: 0 to 4 years; 5 to 9 years; 10 to 14 years; 15 to 19 years; 20 to 24 years; 25 to 29 years; 30 to 34 years; 35 to 39 years; 40 to 44 years; 45 to 49 years; 50 to 54 years; 55 to 59 years; 60 to 64 years; 65 to 69 years; 70 to 74 years; 75 to 79 years; 80 to 84 years; and over 85 years of age.

Deaths registered by residence location were included in the study when the cause of death was melanoma. The exclusion criteria were undefined age and residence in death records. A total of six deaths were excluded from the sample.

Data correction utilized death information from MIS (DATASUS website) as well as the number of corrected and re-distributed deaths 
considering age, sex, and adjustment in accordance with the completeness degree of death records. Ill-defined causes of death also resulted in re-distribution. These data, however, are restricted to CID-10 chapters. A correction factor was calculated for each age group, period, region and sex, based on the difference between the number of deaths notified to MIS due to neoplasms and re-distributed deaths (also based on Chapter II, neoplasms, of CID-10) and the total number of deaths notified to MIS. The value 1 (multiplication neutral factor) was added to the difference obtained, resulting in a correction factor for deaths due to neoplasms. The value was applied to the number of notified melanoma deaths, assuming a correction pattern similar to the pattern of neoplasms.

For the years 1998 and 1999, for which corrected data were not available on Datasus, the correction factor was calculated separately for the year 2000. The factor established for 2000 was applied to 1998 and 1999 melanoma mortality data. Also, mortality rates were adjusted in accordance with the world standard population (ASW) per 100,000 inhabitants ${ }^{9,10}$, through direct standardization $^{11}$. Age standardization followed the Sergi-Doll 1996 model. Rates (brute and standardized) were expressed in values per 100,000 inhabitants ${ }^{9}$, and represent five-year data.

Software NORDPRED (Cancer Registry of Norway, Oslo, Norway) is a statistical package of predictive models, written for software " $\mathrm{R}$ ", and was utilized to calculate projections through the age-period-cohort method, usually applied in incidence and mortality studies. The proposed interval was 5 years for each evaluated cohor $\mathrm{t}^{12}$. Herein the projections were made until 2032 and the evaluation verified the share of projection changes attributable to alterations in population size and structure and due to modifications in death risk by melanoma. The evaluation compared the last observed period (2008-2012) with the last projected period (2028-2032), in accordance with ${ }^{13}$ :

$$
\begin{aligned}
& \Delta t o t=\Delta \text { risk }+\Delta p o p \\
& =(\mathrm{N} f f f-\mathrm{Nooo}) \\
& =(\mathrm{N} f f f-\mathrm{Noff})+(\text { Noff }-\mathrm{Nooo})
\end{aligned}
$$

where $\Delta \mathrm{tot}=$ total variation; $\Delta$ risk $=$ variation caused by changes in cancer death risk, $\Delta p o p=$ variation caused by changes in age groups and population size, $N f f f=$ number of predicted cases for the last projected period, Nooo= Number of cases observed in the last observed period, Noff
$=$ Expected number of cases in the last projected period, with application of the rates from the last observed period, Nfff - Nooo $=$ Annual modification in the number of cases.

After projections were made, trend analysis was carried out with Joinpoint Regression Pro$\mathrm{gram}^{14}$, version 4.2. Standardized melanoma mortality rates were utilized for calculations of trends for each region and for Brazil, separating the analysis by sex. The trend of a specific aggravation was evaluated in accordance with a significant modification in the evolution pattern of the disease, throughout time, characteristics of time trend studies. The model that enables the best fit in relation to the number of joinpoints must be applied. Expression of the joinpoint utilized the year that corresponded to half the period during which a significant change was identified in trend graphics.

The Annual Percentage of Change (APC) was calculated for each segment, searching for statistical significance in a $95 \%$ confidence interval. The set of APC values for each period constituted the graph, and significant modifications in the curve represent the number of joinpoints ${ }^{15}$. The terms "increase" and "decrease" were utilized to describe death rates and explain trends for the periods with statistical APC significance, with $p$ $<0.05$. Cases with no significance were treated as stability.

\section{Results}

During the period between January 1,1998 and December 31, 2012, a total of 15,542,999 deaths were recorded in Brazil. Of these, 2,237,346 were caused by neoplasms, of which $1,203,599$ (53.8\%) occurred in men and 1,033,500 (46.2\%) in women. For the considered time period, the total of deaths by melanoma was 18,048 .

Table 1 presents the number of corrected deaths, separated by age groups $(0-19,20-39,40$ 59 and 60 and over) for each region of the country, along with brute and standardized rates. The selection of summarized age groups was based on the distribution of deaths by age, and rates were expressed in values per 100,000 inhabitants.

Higher mortality rates were found in the South region, and the lowest rates were identified in the North and Northeast regions. The youngest age group (0-19) presented the lowest number of deaths by melanoma for all regions.

In Brazil, the projections were characterized by decreasing mortality rates for men and wom- 


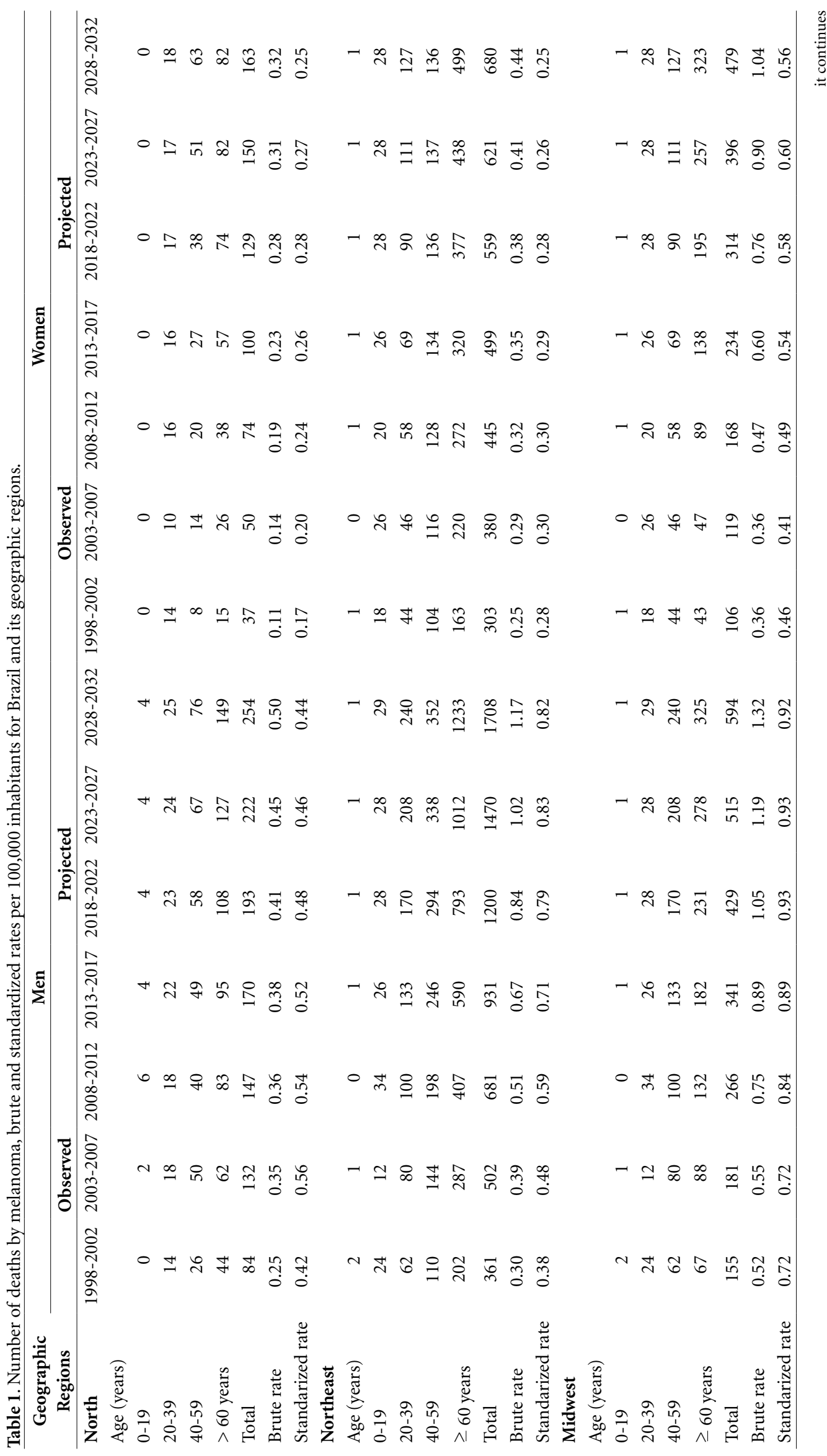




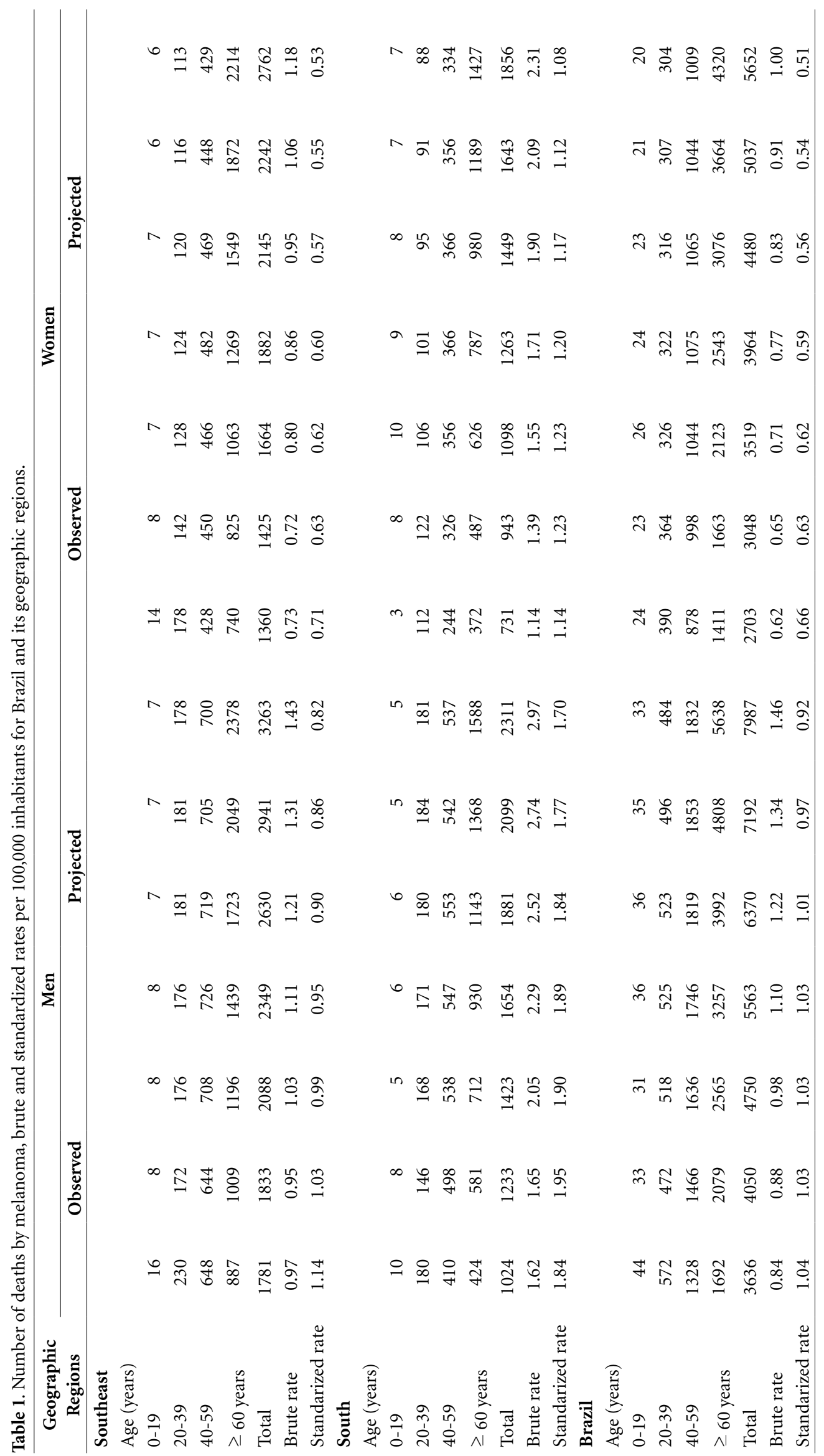


en. Regarding the geographic regions, differences were mainly found between the trends of the South and Southeast regions and the remaining regions.

Analysis of the modifications that occurred throughout time identified whether changes occurred due to an increase in the death risk by melanoma or shifts in population structure or size (Figures 1 and 2). For such analysis, the last period of observed data (2008-2012) was compared with the last period of projected data (2028-2032). The difference in the number of deaths in both periods was represented by "N"; the percentage "change" refers to the difference between the amount of projected deaths and the amount of deaths expected if the projected population (2028-2032) maintained the same population structure of the last observed period (2008-2012). The "risk" represents, in percentage terms, how much of the change in the number of deaths in the two considered periods is related to an increase or decrease in melanoma death risk. "Population" is related to how much of the difference between the number of deaths occurred due to changes in size and structure of the population, for the two considered periods.

For men, the North, South and Southeast regions presented lowest adjusted mortality rates for the projected period in comparison with the observed period. For these regions, the change in absolute number of deaths occurred due to changes in population structure, although there was a reduction in death risk by melanoma. The Northeast and Midwest regions presented both factors influencing the number of deaths.

For women, the South, Southeast and Northeast regions presented lowest adjusted mortality rates for the projected period in comparison with the observed period. In these regions, there was a reduction in death risk by the disease, with modifications in the number of deaths explained by population structure changes. For the North and Midwest regions, the changes occurred predominantly due to changes in population structure.

Regarding trend analysis, there was a significant reduction for men $(\mathrm{APC}=-0.4$; CI95\% $=-0.6 ;-0.1 ; \mathrm{p}<0.01)$ and women $(\mathrm{APC}=-0.8$; CI95\% $=-0.9 ;-0.7 ; \mathrm{p}<0.01$ ), with no joinpoints in the period (Table 2). Regarding the geographic regions, trend analysis for the North region indicated stability $(p=0.5)$. In women, for the same region, there was a joinpoint in 2020. The Northeast region presented one joinpoint in 2015 for men and in 2010 for women. In the Midwest, there were increasing trends for men and women, while the Southeast region indicated decreasing trends for both sexes. The South region presented decreasing trends for men and stability $(\mathrm{p}=0.1)$ for women.

The presence of joinpoint (significant change in the trend curve) indicated a change in the evolution pattern of the mortality standardized rates, dividing analysis into two periods (before and after the joinpoint occurred). For those regions that did not present joinpoint, modification of rates throughout the years followed the same evolution pattern for the studied temporal interval, as shown in Table 2.

\section{Discussion}

When evaluating trends and projections for melanoma mortality in Brazil, differences were identified across geographic regions and different patterns were found, which demonstrate the epidemiological diversity of the country. The highest rates were recorded in the South region, while the lowest rates occurred in the North and Northeast regions.

It must be highlighted that, although there were different patterns for mortality trends, projections indicated increases in the brute number of deaths for all regions. This fact is mainly justified by changes in population size and structure ${ }^{13}$, except for the Northeast region for men and Midwest for both sexes, where the increase was also related to higher death risk by melanoma.

High melanoma mortality rates were found in Europe, mainly in the East and South regions. Mortality rates in Europe vary between 1.5 and 5.2 per 100,000 inhabitants ${ }^{16}$, which is above the values found for Brazil. In Nordic countries, as well as in Europe, higher figures were found for men $^{17,18}$, which could be associated with detection of disease in more advanced stages ${ }^{16,19}$. In Croatia and Belgium, mortality trends indicated increasing patterns for both sexes ${ }^{20,21}$, while in Holland ${ }^{16}$ and Spain ${ }^{22}$ increasing rates were verified for men and stability for women, with higher mortality for men. In Lithuania, male survival was approximately $10 \%$ lower than female rates ${ }^{19}$, corroborating the previous studies. Australia presented stable mortality trends for men and women ${ }^{23}$ and, in the USA, a study has estimated a possible reduction of approximately $20 \%$ in cases between 2020 and 2030 if effective prevention occurs in the country $y^{24}$.

Although incidence rates have increased globally, melanoma mortality has been decreasing. This fact is probably associated with im- 


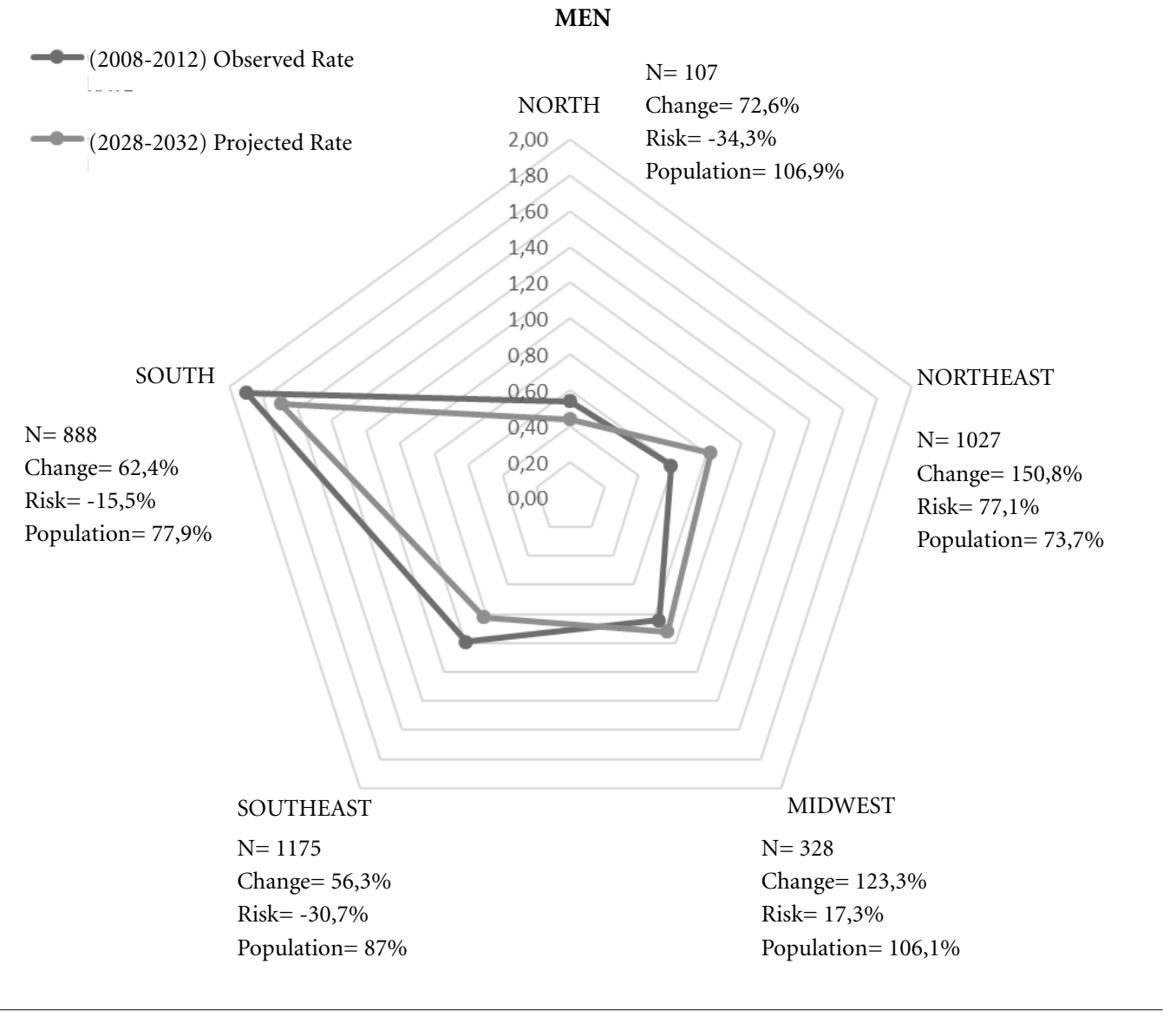

Figure 1. Changes in the number of deaths, risk and population size and structure for men.

provements in diagnoses, which enable early identification of the disease ${ }^{25}$, and is the best way to prevent deaths by melanoma ${ }^{26}$.The findings herein presented revealed reductions in mortality rates in Brazil for both sexes, although different behaviors were found when analyzing trends by geographic region.

Regarding mortality, literature is consensual and presents higher rates in men. This fact is justified by difficulties in monitoring the treatment, late diagnosis, life habits, and due to the fact that men protect themselves less from the sun ${ }^{24}$. However, a North-American study has identified an opposite behavior, with higher exposition to the sun among young women and higher number of melanoma diagnoses than men, possibly related to artificial/indoor tanning practices among women $^{27}$. This aspect does not apply to Brazil, as indoor tanning equipment have been banned in the country ${ }^{28}$.
Although there is divergence regarding sun exposure in different age groups, scientific literature reports higher survival rates in women ${ }^{29}$. The findings herein presented agreed with existing published scientific literature, with a higher number of deaths for men in all periods, and all regions. In Brazil, this fact is probably associated with late detection in men, with diagnosis in more advanced stages.

Evaluation of the social inequalities and health policies explains the difference identified in the extent and number of health policies directed to women in $\mathrm{Brazil}^{30}$, with a more structured health network. This fact, along with the lower participation of men in healthcare/awareness, generates important differences.

The geographic pattern of the disease is contradictory in Brazil, as highest rates were registered in the South region, where sun exposure is lower when compared to more equatorial lo- 


\section{WOMEN}

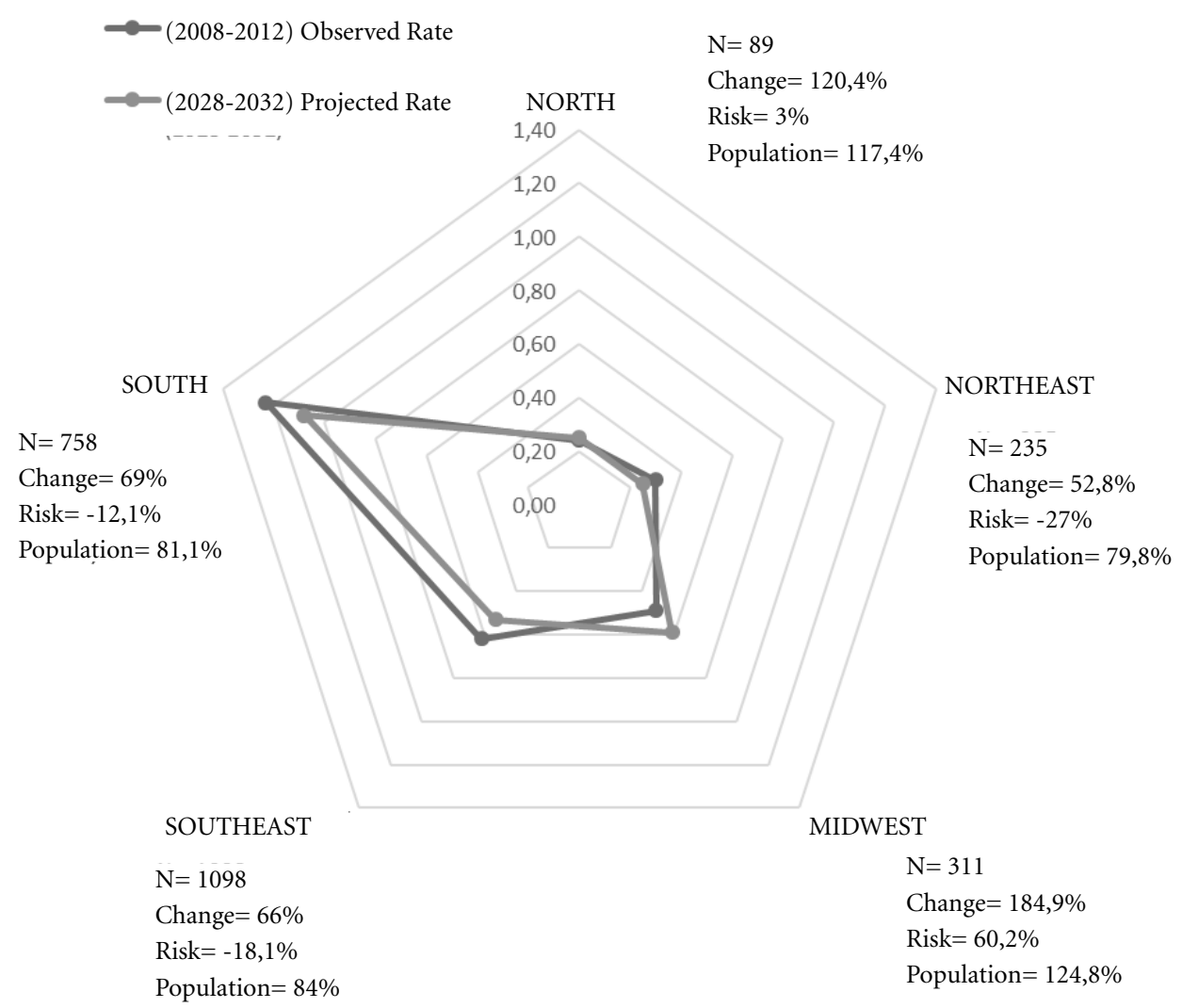

Figure 2. Changes in the number of deaths, risk, and structure and size of population, for women.

cations. The phenotype factor probably acts as a confounding factor, as people with darker skin present lower risks of developing melanoma and non-melanoma skin cancer $^{31}$. Therefore, when isolating white-skin individuals, analysis of the geographic pattern would be more reliable; this fact was proposed by a British study, when observing the inversion of the gradient in some age groups $^{32}$.

The 2010 Brazilian census corroborates with the fact that there is influence of phenotype in the results, showing that there is a higher proportion of Caucasians in South Brazil (more than 70\%), while the North and Northeast regions presented percentages under $40 \%$, with pardos predominating (over $50 \%)^{33}$. In this way, considering melanoma as more frequent in white-skin ${ }^{34}$, distribution of population is a possible explanation for the inversion found herein, despite the broad miscegenation that occurs in Brazil.
In this context, the factors related to phenotype and unprotected sun exposure tend to increase melanoma risks. This can be observed in people that have to work outdoors, exposed to the sun, with important health consequences. A Canadian study reported the occurrence of melanoma in body areas exposed to sun during labor activities $^{35}$, and in Brazil, rural workers presented more skin cancers (approximately 90\%) in areas exposed to solar radiation. It is known that workers exposed to solar radiation present higher incidence of cancer when compared to other professionals. These data point towards the necessity of health policies to reduce work-related illnesses ${ }^{36}$.

Regarding socioeconomic factors, incidence of melanoma is higher in regions with higher purchasing power. In North European countries, a possible explanation is the sun exposure habits of people within this higher income group, 
Table 2. Dynamic trends for melanoma mortality in Brazil and its geographic regions, between 1998 and 2032.

\begin{tabular}{lcrrrrrr}
\hline & APC1a & \multicolumn{2}{c}{ CI 95\% } & Joinpoint & APC2b & \multicolumn{2}{c}{ CI 95\% } \\
\hline Men & & & & & & & \\
North & -0.3 & -1.4 & 0.8 & -- & -- & -- & -- \\
Northeast & $4.4^{*}$ & 3.2 & 5.7 & 2015 & 0.9 & -0.2 & 2.1 \\
Midwest & $1.0^{*}$ & 0.4 & 1.5 & -- & -- & -- & -- \\
Southeast & $-1.0^{*}$ & -1.2 & -0.9 & -- & -- & -- & -- \\
South & $-0.3^{*}$ & -0.6 & 0 & -- & -- & -- & -- \\
Brazil & $-0.4^{*}$ & -0.6 & -0.1 & -- & -- & -- & -- \\
Women & & & & & & - & \\
North & $2.6^{*}$ & 1.2 & 3.9 & 2020 & -1.5 & -5.6 & 2.8 \\
Northeast & 0.7 & -0.7 & 2.2 & 2010 & $-1.0^{*}$ & -1.4 & -0.5 \\
Midwest & $1.2^{*}$ & 0.5 & 1.9 & -- & -- & -- & -- \\
Southeast & $-0.9^{*}$ & -1.1 & -0.6 & -- & -- & -- & - \\
South & -0.3 & -0.7 & 0.1 & -- & -- & -- & - \\
Brazil & $-0.8^{*}$ & -0.9 & -0.7 & -- & -- & -- & - \\
\hline
\end{tabular}

$\mathrm{APCla}=$ annual percentage change for the first period. APC2b $=$ annual percentage change for the second period. ${ }^{*}$ Statistically significant data.

during recreational activities ${ }^{37}$; this fact was also observed in Holland ${ }^{16}$. In Brazil, higher mortality values are registered in the South and Southeast regions, despite decreasing values being observed throughout the study period. It is important to remark that least economically favored areas present more deficient health network structure, which could cause under-registering and increase of discrepancies in these registers. This could have occurred in the North and Northeast regions.

Finally, the last point to be made in data analysis is the evaluation of quality, which can be verified through the assessment of the degree of completeness of medical records, the validity, and coverage of mortality data. MIS presents $>90 \%$ coverage for the Brazilian population ${ }^{38}$, however the quality of death records is different across regions ${ }^{39}$. There is higher coverage in the South, Southeast and Midwest regions, in opposition to the North and Northeast regions. Other issues that can occur include: under-registry of vital events, mistakes in death certificates, as well as difficulties in the coverage of the system, and in data transmission between MIS and DATASUS. However, this study implemented corrections in the number of registered deaths to minimize these effects.

In Brazil, the discrepancies verified between the assistance networks for women and men must be highlighted, along with the lower involvement of men in the process of health prevention. It is essential, therefore, to better adequate health policies to the epidemiological reality experienced by the population, mainly when studying the individual consequences of cancer and the social and labor contexts of the person affected.

Regarding the limitations encountered herein, ecological fallacy can be mentioned, which is inherent to ecological studies, and also the inference that melanoma mortality data correction follows the pattern of other types of cancer. These limitations did not hinder the wide analysis of melanoma in Brazil or the recognition of regional differences and the importance of the creation of preventive policies against the disease. These policies are related to health education, directed to prevention through the decrease of exposition to risk factors, besides the practice of health life habits. These attitudes help early detection, which enables better treatment conditions and higher possibilities of cure, besides preventing the illness in some cases.

It can be concluded that several factors can explain the regional differences encountered in Brazil, such as environmental and individual determinants (e.g., phenotype and behavior). Despite national decreasing trends, least developed regions of the country presented increased rates in the observed period that do not continue in the projections. 


\section{Collaborations}

CA Santos planned, collected, tabulated data, interpreted results and wrote text; DLB Souza planned, interpreted data and contributed with text writing and review.

\section{References}

1. International Agency For Research on Cancer (Iarc). Globocan 2012: Cancer Incidence, Mortality and Prevalence. Worldwide. [cited 2015 Nov 8]. Available from: http://globocan.iarc.fr/

2. Torre LA, Bray F, Siegel RL, Ferlay J, Lortet-Tieulent J, Jemal A. Global Cancer Statistics, 2012. CA Cancer J Clin 2015; 65(2):87-108.

3. Leboit PE, Burg G, Weedon D, Sarasin A. World Health Organization Classification of tumour. Pathology and Genetics of Skin tumours. 3a ed. Lyon: IARC Press; 2006. v 6.

4. Instituto Nacional do Câncer (Inca). Estimativa 2014: Incidência de Câncer no Brasil. Rio de Janeiro: Inca; 2014.

5. Lima AS, Stein, CE, Casemiro KP, Rovere RK. Epidemiology of Melanoma in the South of Brazil: study of a city in the Vale do Itajaí from 1999 to 2013. An Bras Dermatol 2015; 90(2):185-189.

6. Amancio CT, Nascimento LFC. Cutaneous melanoma in the State of São Paulo: a spatial approach. An Bras Dermatol 2014; 89(3):442-446.

7. Magalhães R. Monitoramento das desigualdades sociais em saúde: significados e potencialidades das fontes de informação. Cien Saude Colet 2007; 12(3):667-673.

8. Rapiti E, Guarnori S, Pastoors B, Miralbell R, Usel M. Planning for the future: cancer incidence projections in Switzerland up to 2019. BMC Public Health 2014; 14:102.

9. Jensen OM, Parkin DM, MacLennan R, Muir CS, Skeet RG. Cancer Registration: Principles and Methods. Lyon: International Agency for Research on Cancer Scientific Publications; 1991.

10. Doll R, Payne P, Waterhouse JA. Cancer Incidence in Five Continents. Berlin: Springer; 1966.

11. Bray F, Ferlay J. Chapter 7: Age standardization. In: Forman D, Bray F, Brewster DH, Gombe Mbalawa C, Kohler B, Piñeros M, Steliarova-Foucher E, Swaminathan R, Ferlay J, editors. Cancer Incidence in Five Continents. Lyon: International Agency for Research on Cancer, IARC Scientific Publication; 2014. p. 112-115. Vol. 10.

12. Møller B, Fekjaer H, Hakulinen T, Sigvaldason H, Storm HH, Talbäck M, Haldorsen T. Prediction of cancer incidence in the Nordic countries: empirical comparison of different approaches. Stat Med 2003; 22(17):2751-2766.

13. Møller B, Fekjaer H, Hakulinen T, Tryggvadóttir L, Storm HH, Talbäck M, Haldorsen T. Prediction of cancer incidence in the Nordic countries up to the year 2020. Eur J Cancer Prev 2002; 11(Supl. 1):S1-S96.

14. National Cancer Institute. Surveillance Research Program. Methods and tools. Joinpoint Trend Analysis Software [computer program]. Version 4.0, USA.

15. Kim HJ, Fay MP, Feuer EJ, Midthune DN. Permutation tests for joinpoint regression with applications to cancerrates. Stat Med 2000; 19(3):335-351.

16. de Vries E, Schouten LJ, Visser O, Eggermont AMM, Coebergh JWW. Rising trends in the incidence of and mortality from cutaneous melanoma in the Netherlands: A Northwest to Southeast gradient? Eur J Cancer 2003; 39(10):1439-1446. 
17. Storm HH, Kejs AM, Engholm G, Tryggvadóttir L, Klint A, Bray F, Hakulinen T. Trends in the overall survival of cancer patients diagnosed 1964-2003 in the Nordic countries followed up to the end of 2006: the importance of case-mix. Acta oncol 2010; 49(5):713724.

18. Barbaric J, Sekerija M, Agius D, Coza D, Dimitrova N, Demetriou A, Safaei Diba C, Eser S, Gavric Z, Primic-Zakelj M, Zivkovic S, Zvolsky M, Bray F, Coebergh JW, Znaor A. Disparities in melanoma incidence and mortality in South-Eastern Europe: Increasing incidence and divergent mortality patterns. Is progress around the corner? Eur J Cancer 2016; 55:47-55.

19. Stang A, Valiukeviciene S, Aleknaviciene B, Kurtinaitis J. Time trends of incidence, mortality, and relative survival of invasive skin melanoma in Lithuania. Eur J Cancer 2006; 42(5):660-667.

20. Kirac I, Šekerija M, Šimunovi I, Zgaga L, Vrdoljak DV, Kova evi D, Kuliš T, Znaor A. Incidence and mortality trends of gastric and colorectal cancers in Croatia, 1988-2008. Croat Med J 2012; 53(2):124-134.

21. Bleyen L, De Bacquer D, Myny K, Brochez L, Naeyaert JM, De Backer G. Trends in mortality from cutaneous malignant melanoma in Belgium. Int J Epidemiol 1999; 28(1):40-45.

22. Cayuela A, Rodríguez-Domínguez S, Vigil E, ConejoMir JS. Effect of age, birth cohort and period of death on skin melanoma mortality in Spain, 1975 through 2004. Int J Cancer 2008; 122(4):905-908.

23. Coory M, Baade P, Aitken J, Smithers M, McLeod GR, Ring I. Trends for in situ and invasive melanoma in Queensland, Australia, 1982-2002. Cancer Causes Control 2006; 17(1):21-27.

24. Guy Junior GP, Thomas CC, Thompson T, Watson M, Massetti GM, Richardson LC. Vital signs: Melanoma Incidence and mortality trends and projections - United States, 1982-2030. MMWR 2015; 64(21):591-596.

25. Garbe C, Leiter U. Melanoma epidemiology and trends. Clin Dermatol 2009; 27(1):3-9.

26. Robinson JK, Halpern AC. Cost-effective Melanoma Screening. JAMA Dermatol 2015; 152(1):1-3.

27. Lazovich D, Isaksson VR, Weinstock MA, Nelson HH, Ahmed RL, Berwick M. Association Between Indoor Tanning and Melanoma in Younger Men and Women. JAMA Dermatol 2016; 152(3):268-275.

28. Agência Nacional De Vigilância Sanitária (Anvisa). Nota tecnica no 009/2012 - GGTPS/Anvisa. Brasília: Anvisa; 2012.

29. Roh MR, Eliades P, Gupta S, Grant-Kels JM, Tsao H. Cutaneous melanoma in women. Int $J$ Womens Dermatol 2015; 1(1):21-25.

30. Barbosa IR, Costa ICC, Bernal Pérez MM, Souza DLB. As iniquidades sociais e as disparidades na mortalidade por câncer relativo ao gênero. Rev Ciên Plur 2015; 1(2):79-86

31. Roider EM, Fisher DE. Red Hair, Light Skin, and UV-Independent Risk for Melanoma Development in Humans. JAMA dermatol 2016; 152(7):751-753.
32. Wallingford SC, Alston RD, Birch JM, Green AC. Regional melanoma incidence in England, 19962006: Reversal of north-south latitude trends among the young female population. Br J Dermatol 2013; 169(4):880-888

33. Instituto Brasileiro de Geografia e Estatística (IBGE). Censo Demográfico 2010 - Características da População e dos Domicílios - Resultados do Universo. Rio de Janeiro: IBGE; 2011.

34. Popim RC, Corrente JE, Marino JAG, de Souza CA. Câncer de pele : uso de medidas preventivas e perfil demográfico de um grupo de risco na cidade de Botucatu. Cien Saude Colet 2008; 13(4):1331-1336.

35. Elwood JM, Lee JAH. Trends in mortality from primary tumours of skin in Canada. CMAJ 1974; 110(8):913915.

36. Hayashide JM, SguraMinnicelli R, Camilo de Oliveira OA, Mayumi Sumita J, Mie Suzuki N, Albuquerque Zambianco C, Framil Valéria MS, Morrone LC. Doenças de pele entre trabalhadores rurais expostos a radiação solar. Estudo integrado entre as áreas de Medicina do trabalho e Dermatologia, Rev Bras Med Trab 2010; 8(2):97-104.

37. de Vries E, Bray FI, Coebergh JW, Parkin DM. Changing epidemiology of malignant cutaneous melanoma in Europe 1953-1997: Rising trends in incidence and mortality but recent stabilizations in western Europe and decreases in Scandinavia. Int J Cancer 2003; 107(1):119-126

38. Oliveira PPV, Azevedo e Silva G, Curado MP, Malta DC, Moura L. Confiabilidade da causa básica de óbito por câncer entre Sistema de Informações sobre Mortalidade do Brasil e Registro de Câncer de Base Populacional de Goiânia, Goiás, Brasil. Cad Saude Publica 2014; 30(2):296-304.

39. Guimarães RM, Araújo Andrade SSC, Machado EL, Bahia CA, Oliveira MM, Lima Jacques FV. Diferenças regionais na transição da mortalidade por doenças cardiovasculares no Brasil, 1980 a 2012. Rev Panam Salud Publica 2015; 37(2):83-89.

Artigo apresentado em 29/03/2017 Aprovado em 16/07/2017

Versão final apresentada em 18/07/2017 
